\title{
Ulisse Aldrovandi: 0 criador do termo Geologia
}

\author{
Ulisse Aldrovandi: the creator of the "Geology" \\ Andrea Bartorelli ${ }^{1}$, Paulo Masuti Levy ${ }^{2}$, Celso Dal Ré Carneiro ${ }^{3}$ \\ 1 Consultor, São Paulo, SP. E-mail: bartorelligeo@uol.com.br \\ 2 Diretor, Grupo ENGEP, Limeira, SP. \\ 3 Instituto de Geociências, Universidade Estadual de Campinas, Campinas, SP
}

\section{Manuscrito:}

Recebido: 24/04/2014

Corrigido: $31 / 10 / 2014$

Aceito: 04/12/2014

Citation:Bartorelli A., Levy P. M., Carneiro C.D.R. 2015. Ulisse Aldrovandi: 0 Criador do termo Geologia. Terræ Didatica, 11(2):88-93. < http://www. ige.unicamp.br/terraedidatica/> .

Keywords: History of Geology; Geology; teaching-learning; digital treatment of rare books.
ABSTRACT: This article describes excerpts of the original work containing the pioneering contribution of Ulisse Aldrovandi, the creator of the term "Geology" in 1603, in Bologna. As briefly situated in this paper, the origin of the term geology can be mainly due to cultural reasons, most derived from the temporal circunstamces of that time, and the need for a taxonomic articulation of the natural sciences in a higher hierarchical level. The existence of a very rare copy of the 13-book collection, in the city of Limeira, São Paulo, has yelded access to information related on the paper and also emphazises the importance of digitization of valuable personal collections towards making them available to interested people by the Internet.

\section{Introdução: a criação do termo "Geologia"}

Por ocasião do XXXII Congresso Internacional de Geologia de 2004, em Florença, Gian Battista Vai e William Cavazza editaram o louvável volume Four Centuries of the Word Geology: Ulisse Aldrovandi 1603 in Bologna.

A contribuição de Bolonha para o nascimento e desenvolvimento da ciência moderna e das ciências naturais, particularmente a Geologia, decorre sobretudo da grande unidade cultural e cooperação interdisciplinar, envolvendo trabalho em equipe. Nesse contexto, a investigação dos últimos quatro séculos da atuação da universidade no campo da ciência e natureza começa com Ulisse Aldrovandi (Fig. 1), excepcional cientista, filósofo e criador de instrumentos culturais. Linneu e Buffon consideram-no o pai da história natural. A obra original de Ulisse Aldrovandi é extremamente rara. Uma feliz coincidência de fatos e decisões fez com que as treze principais publicações de sua obra fossem parar em território brasileiro na cidade de Limeira, Estado de São Paulo, na biblioteca particular de um dos autores deste artigo (PML).

A publicação de Vai e Cavazza (2004), acima referida, celebra o evento da criação do termo "Geologia", introduzido por Aldrovandi há mais de 400 anos. A ideia de trazer, no ano de 2004, um
Congresso Internacional de Geologia de volta para a Itália, após um jejum de 123 anos, foi concebida em Bolonha, por geólogos bolonheses.

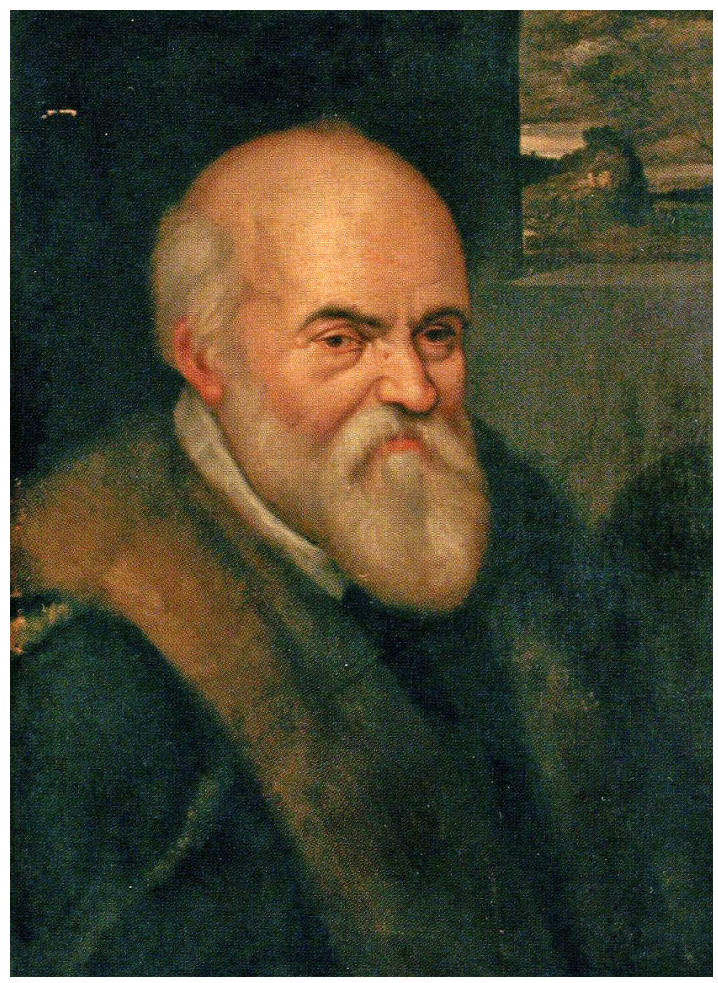

Figura 1. Ulisse Aldrovandi 


\section{Resumo biográfico de Aldrovandi}

Ulisse Aldrovandi nasceu em 11 de setembro de 1522, no período reformista de Martinho Lutero, cujos protestos contra a Igreja Romana, da qual Bolonha fazia parte, tiveram grande influência na cidade natal de Aldrovandi e nele próprio. Uma tia-avó de Aldrovandi foi progenitora do Papa Gregório XIII, promotor da reforma do calendário.

Com forte vocação enciclopédica, Ulisse Aldrovandi logo se envolveu em diversos campos de estudos acadêmicos, como ciências humanísticas, jurisprudência, filosofia, matemática e medicina, que lhe propiciaram o aprendizado do método investigativo do mundo da natureza. Percebeu que o aprendizado a partir apenas de livros não era suficiente, devendo ser complementado com os recursos da visão e do tato. Vangloriava-se de nunca ter descrito algo sem tê-lo tocado com as próprias mãos e sem um exame anatômico, preceito derivado da filosofia do conhecimento das espécies sublunares. Assim, desde a adolescência, Aldrovandi alternava a frequência às aulas com viagens, que acabaram se transmutando em expedições científicas ou, ao menos, em viagens visando a sua instrução.

Com 12 anos apenas, sem avisar a família, viajou a Roma, movido pela mera curiosidade de ver a cidade cujas belezas tinha ouvido decantadas tantas vezes. Daí em diante não parou de viajar, principalmente depois que Luca Ghini, seu professor em Bolonha de 1528 a 1544, o convenceu a se especializar em ciências naturais. Com o tempo, Aldrovandi abandona assim o enciclopedismo e concentra sua paixão de colecionador para o reino dos animais, vegetais e minerais, sem deixar de conceder espaço para objetos etnológicos, arqueológicos e artísticos. Naqueles tempos, as ciências naturais eram consideradas ainda "assunto extraordinário", ou seja, faziam parte da medicina e a complementavam.

Por intermédio de colóquios pessoais como o mestre Ghini, Aldrovandi assimilou o método e as exigências científicas de modo a obter, graças à influência do nome nobre da família, muito respeitado na Bolonha do século XVI, os recursos necessários para a criação da cadeira de "philosophie naturalis de fossilibus, plantis, et animalibus", mantendo-a por 40 anos, até 1600. Pouco depois da criação da cadeira, que desbancou a posição tradicional de medicina, ele criou, em 1568, um jardim botânico público destinado ao uso em ensino e pesquisa. Mais tarde, valendo-se de contatos obtidos por Ghini e adotando as técnicas do seu mentor para secagem de plantas (herbários), Aldrovandi criou um museu de História Natural que satisfez o gosto especial de seu tempo, pelo colecionismo. Era normal, na virada das épocas culturais, a ambição de recapitular o saber com novas sínteses, em função da necessidade de recolocar ordem nos horizontes da mente. Por essa razão, nos tempos de Aldrovandi, multiplicaram-se coleções enciclopédicas sob a forma de "câmaras de maravilhas" (Wunderkammern), teatros do mundo, bibliotecas, museus, arquiteturas simbólicas, obras pansóficas.

$\mathrm{Na}$ epistemologia do final dos anos 1500 , que alcançou maior desenvolvimento no decorrer do século seguinte, co-existiram duas visões opostas: de um lado, a fragmentação das coisas, conferindo-lhes forte individualização, de modo a formar uma exuberante totalidade fragmentada; de outro lado, a aspiração à unidade e à harmonia. Seria, assim, incorreto caracterizar Aldrovandi como um simples colecionador de uma pletora de plantas, animais e fósseis (entendendo-se por fósseis todos os achados encontrados em escavações do subsolo ou aflorando no terreno devido a erosão), uma vez que deve ser acrescentada a essa atividade uma conotação taxonômica a qual, bem antes de Lineu, não tem paralelo quanto à sua natureza e rigor sistemático. O museu de Aldrovandi não se limita a conservar o saber, pois o descreve organicamente para rendê-lo mais funcional e efetivo como instrumento de ensino, por meio da intervenção da arte da memória.

Da mesma forma que outros cientistas aristotélicos de seu tempo, Aldrovandi se encarregou de organizar o caos da realidade por meio de sua arte, reunindo a multiplicidade dos fenômenos naturais em estreita cooperação entre a experiência sensorial e os princípios universais. A inquietude decorrente disso acompanhou Aldrovandi durante toda sua vida, inquietação típica dos praticantes de um dos passatempos mais em voga na época, o colecionismo.

\section{Testamento de Aldrovandi e a introdução da palavra Geologia em 1603}

O termo Geologia é pela primeira vez registrado no testamento de Aldrovandi. Sua preocupação com a preservação de incalculável acervo de livros e objetos da natureza que reuniu é manifestada em testamento, um monumento ao orgulho de um homem que tinha consciência de ter realizado uma obra inédita, inestimável para a humanidade 
e merecedora de preservação para uso público. Até o ano de 1572 ele já tinha estudado e coletado mais animais e plantas que Aristóteles. Trata-se do mais orgânico e concreto manifesto de museologia científica ditado por um cientista em seu leito de morte. Ao mesmo tempo, é paradoxal esse reconhecimento ter sido registrado por um oficial testamenteiro: a dignidade das primeiras disciplinas individuais "Botanologia, Zoologia e Giologia". Para evitar ambiguidade, Aldrovandi fornece uma definição operacional imediata para o termo: a ciência dos fósseis, em sentido amplo, como era bastante comum naqueles tempos (Vai e Cavazza 2004, p.70-71). Desse modo, a ciência Giologia, que denominara em seu testamento, fôra referida logo antes de Botanologia e Zoologia, de modo a destacá-las do conjunto de ciências naturais derivadas da filosofia natural escolástica, não sem no entanto propor e introduzir uma busca ordenada...

\begin{abstract}
“(..) por uma nova abordagem da natureza, a ser estudada primeiro no campo e depois racionalmente reconstruída 'como em um teatro'. Experimentação e teatralidade: este fôra o novo Renascimento e cenário para a pesquisa científica e ensino acadêmico" (Vai e Cavazza 2004, p.68).
\end{abstract}

A preocupação de Aldrovandi consistia em garantir a preservação de sua herança não para os "direitos de família" (Vai e Cavazza 2004, p.69), porém, em uma instituição pública permanente, por meio do suporte integral do arcebispo de Bolonha pro tempore, para a execução de seu legado junto com o governador pro tempore e um representante da família. Aquilo que Aldrovandi criara era realmente um museu global, o primeiro a expor materiais de história natural do Novo Mundo. É digno de nota o fato de Aldrovandi ter planejado uma viagem de pesquisa e coleta naturalística nas Américas, dois séculos antes de Alexander von Humboldt (Vai e Cavazza 2004, p.69).

Aldrovandi definiu a nova disciplina como "la Giologia ovvero de fossilibus" ("Geologia, ou sobre o que é desenterrado da Terra”). Uma referência particular é feita à sua grande coleção científica de rochas, fósseis, organismos e minerais que passaria a ser exibida em uma sala dedicada de um museu, que levaria seu nome. Vai (2009) considera surpreendente que uma citação notavelmente semelhante havia sido adotada para o logotipo da Sociedade Geológica de Londres; "quicquid sub Terra est" (“o que está debaixo da terra"), salientando que estaria pois fechada uma "recorrência circular de conceito e terminologia, que começara com Aldrovandi em 1603 e terminara com a Sociedade Geológica em 1807" (Vai 2009, p.181). Este autor relembra ainda que, durante dois séculos, "termos tais como litologia, petrologia, 'oryctology' e geognose foram utilizados mais frequentemente do que a geologia" e que, "quando usada, a geologia teve vários significados diferentes". Ao mesmo tempo, salienta alguns motivos que teriam levado a Itália a perder seu papel de liderança na história da geologia ao final do século XIX: a nova geologia do século XIX, baseada na estratigrafia paleontológica, fôra desenvolvida principalmente na França e na Grã-Bretanha (Vai 2009), duas nações poderosas que "favoreceram a conscientização e popularização

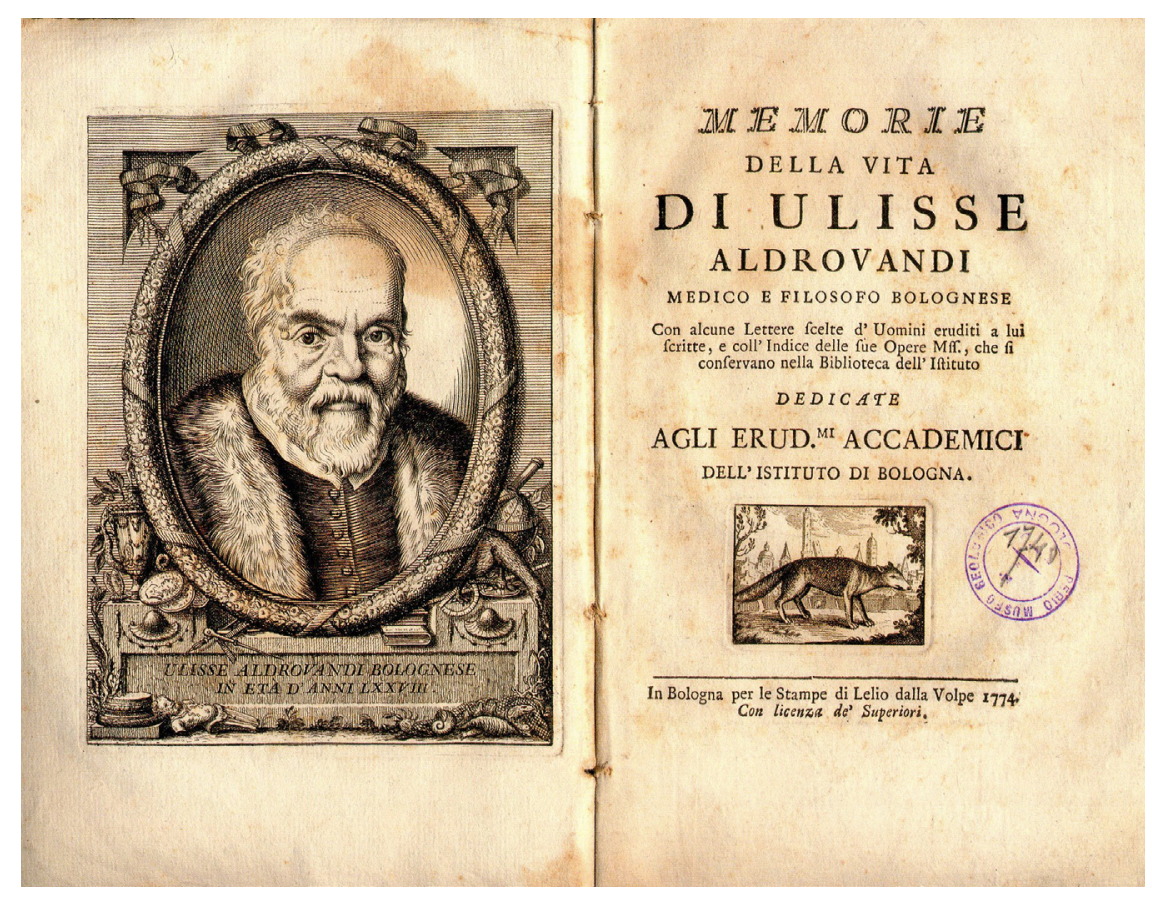

Figura 2. Fronstispício de uma biografia de Ulisse Aldrovandi (Fantuzzi 1774 apud Vai e Cavazza 2004) 


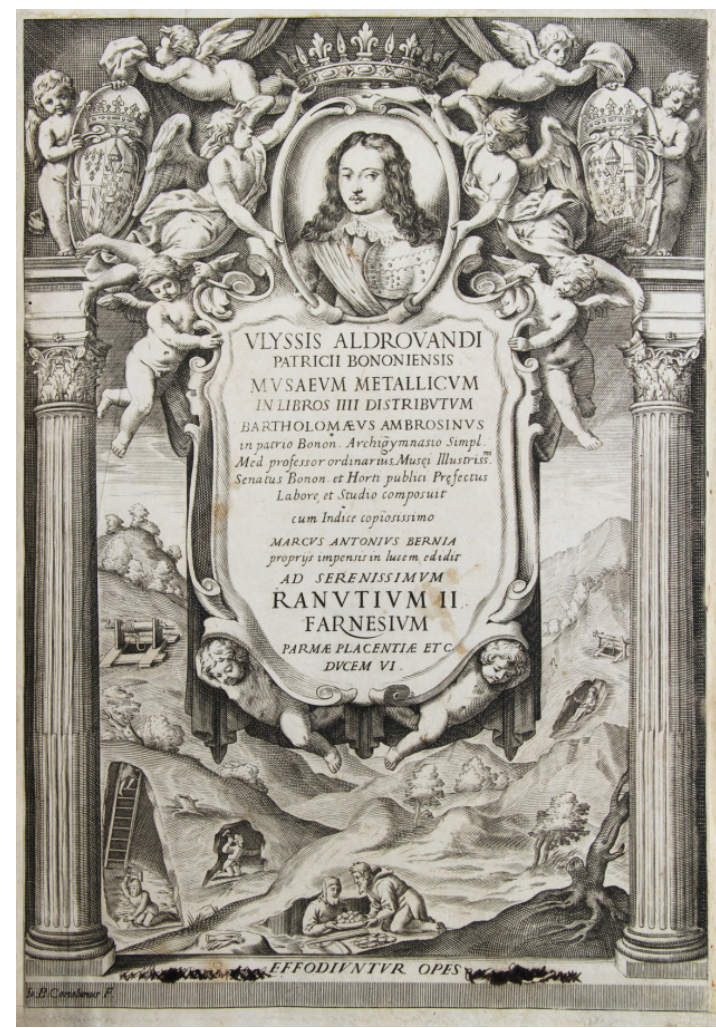

Figura 3. Fronstispício da obra original Musaeum Metallicum de Ulisse Aldrovandi

de uma ciência nacional que não podia ser sentida em países como a Itália e a Alemanha, que ainda não existiam" (Vai 2009, p.180, grifos do original).

\section{A concepção do termo Geologia e sua etimologia}

Vai e Cavazza (2004) assinalam que o fervor artístico, científico e cultural estimulado pelo Humanismo e a Renascença espalhou-se da Itália para o resto da Europa e, com o concomitante progresso econômico, foi responsável pela transferência do debate sobre fósseis do âmbito da filosofia natural para aquele da filosofia geral, incluindo até a cosmologia, que consistia no núcleo das investigações daqueles tempos. Os debates extrapolaram o âmbito acadêmico, espalhando-se em mosteiros, estúdios e paróquias, especialmente na Itália. Foram, assim, surgindo escritos sobre cosmogenia, teorias da Terra e sua história, cujo interesse maior dizia respeito à descrição dos fósseis (Figs. 2 a 4). Esse fato é incontestável tanto na obra de James Hutton, como, em particular, no capítulo 3 dos "Principles of Geology" de Charles Lyell (1830-33, apud Vai e Cavazza 2004, p.72).
Cervato e Frodeman $(2012,2014)$ assinalam a importante contribuição de Hutton e Werner, no século XVIII, com a concepção de tempo geológico, que dá lugar a uma série de desdobramentos que incluem a formulação da Teoria da Evolução e a moderna compreensão dos desafios econômicos e ambientais que a sociedade enfrenta. Além disso, a perspectiva do tempo profundo constitui a mais importante contribuição da Geologia para a Ciência (Gould 1991). A perspectiva do tempo geológico é um desafio fundamental para o ensino-aprendizagem de Ciência, até mesmo porque introduz relevantes questões sobre o "lugar da humanidade no esquema maior de todas as coisas" (Cervato e Frodeman 2014).

Em ambiente intelectualmente favorável, na transição do século XV ao XVI, insere-se a expansão construtiva e urbanística (associadas a escavações) e a atenção crescente para coisas vis (coisas comuns, corriqueiras, pouco valorizadas), e não somente dirigidas a obras de arte (religiosa) e ao engenho (códigos e livros), por parte de mosteiros, bispos e realezas. Os objetos sem valor tornam-se alvo de coleções permanentes para pesquisa, bem além do escopo dos herbários, bestiários e lapidários

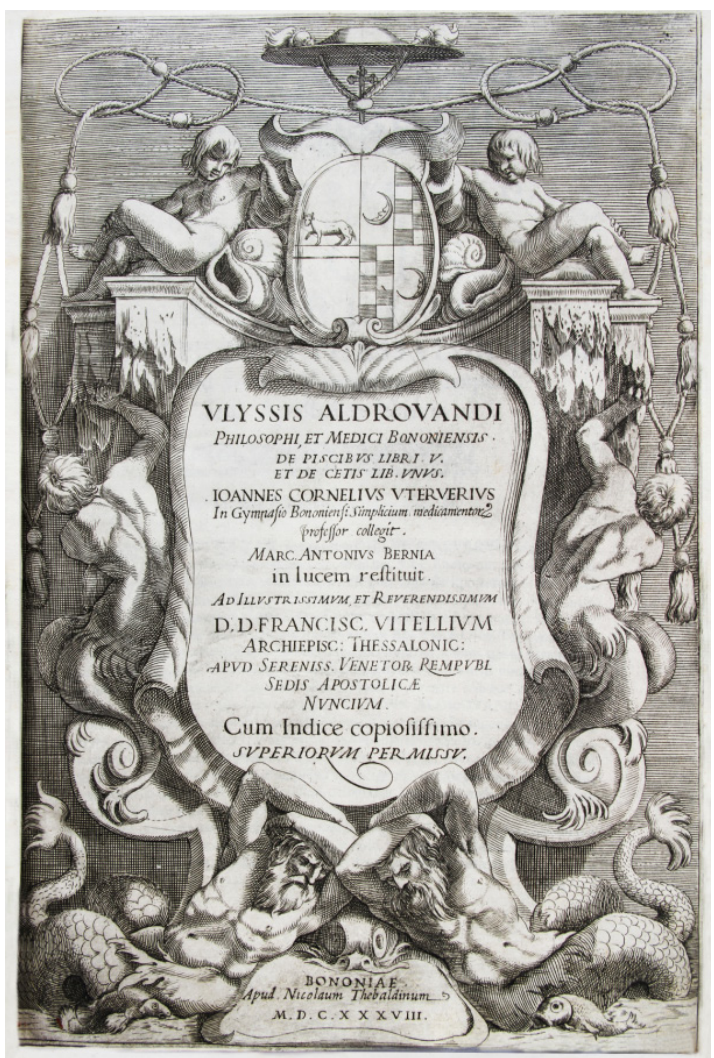

Figura 4. Fronstispício da obra original De piscibus libri $\checkmark$ de Ulisse Aldrovandi 
tradicionais. Trata-se, de fato, do surgimento dos primeiros museus de história natural, nos moldes daquele de Aldrovandi em Bolonha (1547).

Nesse contexto, com um problema filosófico tão aberto e crescente, cada vez mais espelhado em coleções e livros, amadureceu o tempo para o batismo de um nome próprio e adequado à disciplina que estava se ocupando do problema. A explicação é apropriada para o fato de a mente sistemática e organizada de Aldrovandi ter cunhado e introduzido um novo termo na ciência. É possível que ele também tenha imaginado que a nova disciplina, por ele batizada, "desenvolver-se-ia no futuro, uma vez superado o problema epistemológico do nome com o qual ficou sendo conhecida" (Vai e Cavazza 2004, p.72).

\section{A Nova Ciência}

Aldrovandi introduz o termo Geologia (Gortani 1931, 1963 apud Vai e Cavazza 2004), em paralelo aos nomes das disciplinas Botanologia e Zoologia, arrolados em seu testamento logo após o emprego do primeiro termo (Geologia), atribuído a ele. A intenção de Ulisse Aldrovandi era dividir os assuntos naturais (res naturales) em três disciplinas, como explicitado na página 80 do seu testamento, na qual a "Syntaxis rerum naturalium" era dividida em três volumes, um de "Minerais e Fósseis", um de "Plantas" e um de "Animais" (Fig. 5), vale dizer, em ordem taxonômica, "Giologia,...Botanologia, $\mathcal{E}$ Zoologia” (Fantuzzi 1774 apud Vai e Cavazza 2004).

Surge a questão do porquê de Aldrovandi não ter adotado uma denominação pré-existente? Ele poderia ter adotado o termo Mineralogia, cunhado na obra Agricola G. [1530. Bermannus, sive De Re Metallica. Froben, Basileae, 135p.] por Georgius Agricola (nome real: Georg Bauer) conforme tem sido amplamente reconhecido (Morello 2006 apud Vaccari 2012). Aldrovandi usou o termo "minerais" duas vezes em seu testamento e, antes disso, a palavra "pedras", mas para ele, a mineralogia faria parte da nova disciplina; estava convencido de que o escopo da nova disciplina não se limitava ao mundo mineral, mas se estendia ao complexo mundo "mineralizado" e fóssil, bem como a outros diversos componentes não-vegetais e não-animais que ocorrem "dentro" e não apenas "sobre" a Terra. Desse modo, era necessário dispor de um novo nome, geral e abrangente. "Geologia" (Fig. 6) poderia satisfazer a essa necessidade. Isso explica ainda a independência e a não sobreposição com

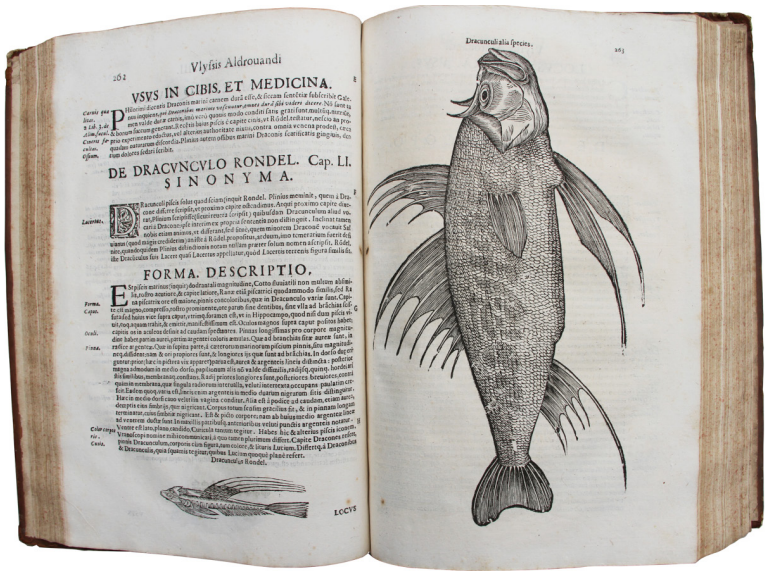

Figura 5. Imagem de peixe da obra original De piscibus libri $V$ de Ulisse Aldrovandi

a Geografia. No plano etimológico, a "derivatio nominis" torna-se óbvia a partir da simetria com a Botanologia e Zoologia, partindo do étimo grego

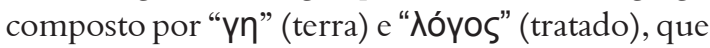
foi transcrito para o latim, língua dos estudiosos, da cultura e da ciência (Vai e Cavazza 2004, p.73).

O termo Geologia, portanto, nasceu com Aldrovandi por razões essencialmente culturais e por necessidade de articulação taxonômica das ciências naturais ao mais alto e generalizado nível hierárquico. Não existiu qualquer pretensão de substituir outros termos mais específicos e consagrados. $\mathrm{O}$ novo termo preencheu o nascente espaço temático-disciplinar ainda vazio, almejando a reunião das disciplinas preexistentes, mais específicas. Um atraso na impressão do testamento de Aldrovandi postergou a adoção do termo Geologia e poderia explicar o crédito tardio da paternidade do novo termo.

Este artigo, ao mesmo tempo em que se soma a outros autores em enaltecer a contribuição de Aldrovandi, valoriza a importância do investimento realizado por pessoas, em suas respectivas coleções particulares, que se somam às públicas, para preservação da memória geológica de um povo. Cada vez mais, a disponibilização de obras raras ao público interessado pela internet deve ser valorizada, embora seja iniciativa dependente da digitalização de acervos pessoais valiosos, como este que ora descrevemos.

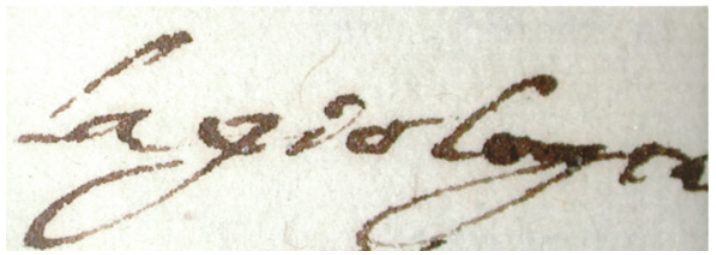

Figura 6. Imagem da palavra Geologia conforme grafada no testamento de Ulisse Aldrovandi 


\section{Referências}

Cervato C., Frodeman R. 2012. The significance of geologic time: cultural, educational, and economic frameworks. The Geological Society of America, Special Paper, n. 486, p.19-27, 2012. URL: doi: 10.1130/2012.2486(03). Acesso 12.09.2014.

Cervato C., Frodeman R. 2014. A importância do tempo geológico: desdobramentos culturais, educacionais e econômicos (trad.). Terra Didatica, 10(1):67-79. URL: http://www.ige.unicamp.br/ terraedidatica/. Acesso 28.08.2014. Fantuzzi G. 1774. Memorie della vita di Ulisse Aldrovandi medico i filosofo bolognese. Bologna, per le stampe di Lello Dalla Volpe. 264p.

Gortani M. 1931. Bibliografia geologica italiana. Parte prima. Opere di carattere generale. Giornale di Geologia, 6, 9-38.

Gortani M. 1963. Italian pioneers in geology and mineralogy. J. World History, 7(2):503-519.

Gould S.J. 1991. Seta do tempo, ciclo do tempo: mito e metáfora na descoberta do tempo geológico. Trad. Malferrari, C.A. São Paulo: Cia. das Letras. 221p.

Morello N. 2003. The question of the nature of fossils in the $16^{\text {th }}$ and $17^{\text {th }}$ centuries. In: G.B. Vai, W. Cavazza. eds. 2003. Four Centuries of the Word Geology. Ulisse Aldrovandi 1603 in Bologna. Bologna:Minerva Edizioni, . p. 127-151.

Vaccari E. 2012. Judging by color in the early history of geology and paleontology. Palaeogeogr., Palaeoclim., Palaeoecol., 367-368:147-152. URL: http://www.sciencedirect.com/science/article/pii/ S0031018212005810\#. Acesso 15.09.2014.
Vai G.B. 2009. Light and shadow: the status of Italian geology around 1807. Geol. Soc., London, Spec. Publ.317:179-202. URL: doi:10.1144/SP317.10. Acesso 15.09.2014.

Vai G.B., Cavazza W. 2003/2004. Four Centuries of the Word Geology: Ulisse Aldrovandi 1603 Bologna / Quadricentenario della parola Geologia: Ulisse Aldrovandi 1603 Bologna. Eds. Gian Battista Vai e William Cavazza: Università di Bologna/ Comitato Organizzatore del $32^{\text {mo }}$ Congresso Geologico Internazionale Firenze 2004 (Minerva Edizioni).

Volumes Biblioteca Paulo Masuti Levy:

- Ornithologiae Tomos Tertius ac Postremus 1637.

- Ornithologiae Tomus alter 1637

- De Animalibus Insectis Libri Septem 1638.

- De Piscibus Libri V et de Cetis Lib unus 1638.

- De Quadrupedibus Solidipedibus Volumen Integrum 1639.

- Historiae Serpentum Draconum Libri duo 1639.

- Monstrorum Historiae cum Paralipomenis Historiae Omnium Animalium 1642.

- De Reliquis Animalibus Exanguibus Libri quatuor 1642.

- Quadrupedum Omnium Bisulcorum Historia 1642.

- De Quadrupedibus Digitatis Viviparis Libri tres et de Quadrupedibus Digitatis oviparis Libri duo 1645.

- Ornithologiae hoc est de Avibus Historiae Libri XII 1646.

- Musaeum Metallicum in Libros IV 1648.

- Dendrologiae Naturalis Scilicet Arborum Historiae

Libro duo - Sylua Glandaria, Acinosunque Pomarium 1671.

Obs.: A coleção dos livros de Ulisse Aldrovandi pertenceu anteriormente à biblioteca do médico paulista Dr. Cássio Galvão Monteiro.

RESUM0: Este artigo comenta e descreve excertos do testamento que contém a contribuição pioneira de Ulisse Aldrovandi, ao introduzir na literatura em 1603 o termo "Geologia", na cidade de Bolonha, Itália. No contexto da época, brevemente situado na comunicação, o nascimento do termo Geologia deve-se a razões essencialmente culturais e à necessidade de articulação taxonômica das ciências naturais em elevado nível hierárquico. A existência de uma coleção (treze volumes) sobre Ulisse Aldrovandi, muito rara, na cidade de Limeira, Estado de São Paulo, na biblioteca pessoal de um dos autores (PML) permitiu ter acesso às informações relatadas no artigo e conduz à valorização de iniciativas de digitalização de acervos pessoais valiosos e sua disponibilização aos interessados pela internet.

PALAVRAS-CHAVE: Geologia; História da Geologia; ensino-aprendizagem; digitalização de obras raras. 